\title{
Chiari malformation type 1 presenting as unilateral progressive foot drop: a case report and review of literature
}

\author{
Chamara Jayamanne ${ }^{1,2^{*}}$, Lakkumar Fernando ${ }^{3}$ and Sachith Mettananda ${ }^{4}$
}

\begin{abstract}
Background: Foot drop is a disabling clinical condition with multiplicity of causes, which requires detailed evaluation to identify the exact aetiology. Here, we report an extremely rare cause of foot drop in a child, which if not recognized early, could lead to multiple complications.

Case presentation: A 6-year-old girl presented with difficulty in walking and left sided foot droop for1-month duration. On examination she had reduced muscle power in dorsiflexors and plantar flexors and diminished knee and absent ankle jerk in the left side. Sensory loss was noted in $L 4$ and $L 5$ dermatomes on the left side. Superficial abdominal reflex was absent on the left side while preserved in the right. Nerve conduction and electromyography revealed nerve root or spinal cord cause for the foot drop. These results prompted ordering MRI spine and brain which revealed Chiari malformation type-1 with holocord syrinx extending from the cervicomedullary junction to conus medullaris.
\end{abstract}

Conclusions: This case highlights the importance of considering broad differential diagnosis for foot drop and value of the complete neurological examination including superficial reflexes in arriving at a diagnosis. Prompt diagnosis helped to early neurosurgical referral and intervention which is an important prognostic factor.

Keywords: Unilateral foot drop, Syringomyelia, Chiari malformation

\section{Background}

Foot drop is a disabling neurological condition which requires careful evaluation to identify the cause. Differential diagnosis for foot drop is broad however, mostly involve disorders of the peripheral nervous system. Here, we present an extremely rare central cause of foot drop in a child, which if not recognized early, could lead to multiple complications.

\section{Case presentation}

A 6-year-old girl presented with progressively worsening difficulty in walking and left sided foot droop for1monthduration. There was no pain, paresthesia or sensory symptoms in limbs and she did not complain of headache or backache. There was no history of trauma. She is the second child of non-consanguineous parents

\footnotetext{
* Correspondence: chamarajy@gmail.com

${ }^{1}$ North Colombo Teaching Hospital, Ragama, Sri Lanka

${ }^{2}$ Colombo, Sri Lanka

Full list of author information is available at the end of the article
}

and had an uncomplicated birth and perinatal period. She was apparently well except for frequently relapsing nephrotic syndrome for which she was on $5 \mathrm{mg}$ of prednisolone and $60 \mathrm{mg}$ of levimasole on alternative days. Her last (fourth) relapse was six months ago.

On examination she was averagely built for her age. Nervous system examination revealed wasting of anterior compartment of the left leg and reduced muscle power in distal muscle groups on the left side - 0/5 in dorsiflexors and $3 / 5$ in plantar flexors. Muscle power in proximal muscles of the left lower limb, all muscle groups in the right lower limb and both upper limbs were normal (5/5). Left knee jerk was diminished and left ankle jerk and left plantar response were absent. Sensory loss was noted in L4 and L5 dermatomes on the left side. Superficial abdominal reflex was present on the right side however was absent on the left side which pointed towards a central cause for foot drop. All other systems including blood pressure were clinically normal. 
Basic investigation including full blood count, erythrocyte sedimentation rate and C-reactive protein were unremarkable and rheumatoid factor and antinuclear antibodies were negative. Nerve conduction studies revealed normal distal amplitude, latency and velocities in common fibular nerve (tested at extensor digitorum brevis) in the left (amplitude $3.3 \mathrm{mV}$; latency $2.8 \mathrm{~ms}$; velocity $59 \mathrm{~m} / \mathrm{s}$ ) and right (amplitude $2.9 \mathrm{mV}$; latency $3.1 \mathrm{~ms}$ ) sides and tibial nerve (tested at abductor hallucis)in the left side(amplitude $20.8 \mathrm{mV}$; latency $4.2 \mathrm{~ms}$ ). Sural nerve sensory response was normal. Electromyography (EMG) at left tibialis anterior revealed fibrillations and scanty motor unit potentials (MUP). EMG of left medial gastrocnemius and right tibialis anterior were normal. These results suggested prompt imaging of the spine. MRI of the lumbosacral spine was arranged and was later expanded to whole spine and brain. This revealed a holocord syrinx extending from the cervicomedullary junction to conus medullaris (Fig. 1A and B) and Chiari malformation type 1 without bony deformities (Fig. 2).

The patient was referred to the neuro-surgical team and is awaiting surgery which will include suboccipital craniectomy, C1 laminectomy and duroplasty decompressing foramen magnum. Neuro-rehabilitation was commenced and an ankle foot orthosis was offered for the foot drop.

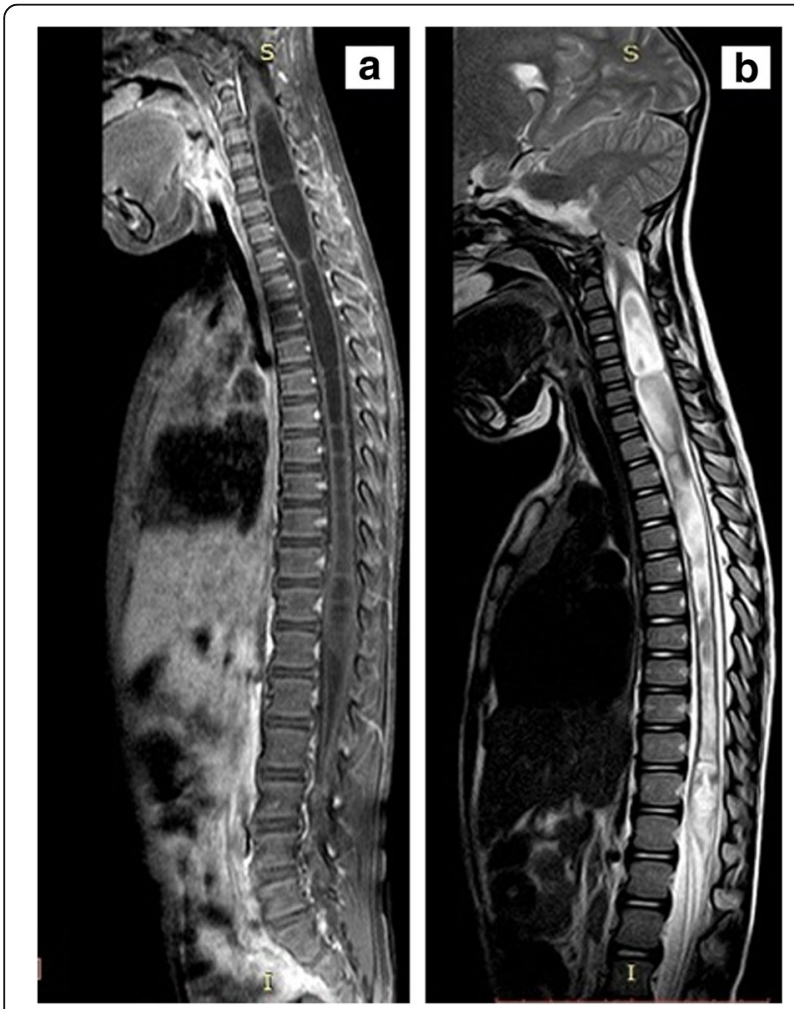

Fig. 1 a Sagittal T1-weighted sequence of MRI of thoracolumbar spine showing hypointense central cavitary lesion involving whole cord up to conus medullaris. b Sagittal T2-weighted sequence of MRI of thoracolumbar spine showed central cavitary lesion extending down to the conus medullaris.

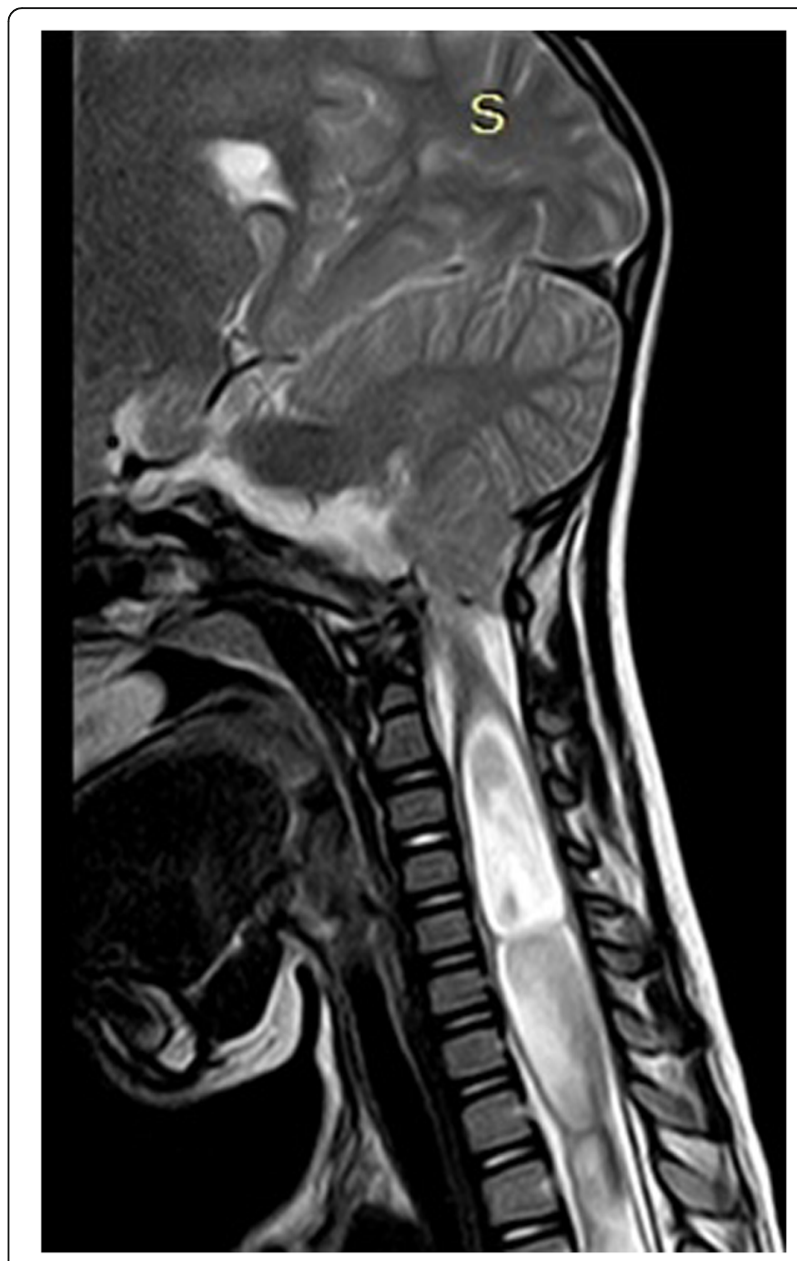

Fig. 2 Sagittal T2-weighted MRI of cranio-vertebral junction and cervical spine showing tonsillar herniation and central cavitary lesion suggestive of Chiari malformation type 1 and syringomyelia

\section{Discussion and conclusions}

Identification of the exact cause is the most important component of the management of foot drop. Causes are diverse, consists of a broad range of pathologies however, lesions in the peripheral nervous system which include, common peroneal neuropathy, L5 radiculopathy, lumbosacral plexopathy, hereditary neuropathies, mononeuritis multiplex and anterior horn cell diseases predominate. Rarely, central lesions including brain tumours and tuberculomas can cause foot drop. In this report we have described an extremely rare presentation of a central lesion-Chiari malformation type 1- presenting as unilateral foot drop.

Chiari malformations refer to a spectrum of congenital hind brain abnormalities affecting structural relationships between the cerebellum, brain stem, the upper cervical cord and the bony cranial base [1]. Chiari malformation type 1 is the most common form which usually presents with recurrent headache, neck pain, urinary frequency, and progressive lower-extremity spasticity during adolescence or 
Table 1 Clinical and neurophysiological findings of previous case reports which describe syringomyelia presenting as foot drop

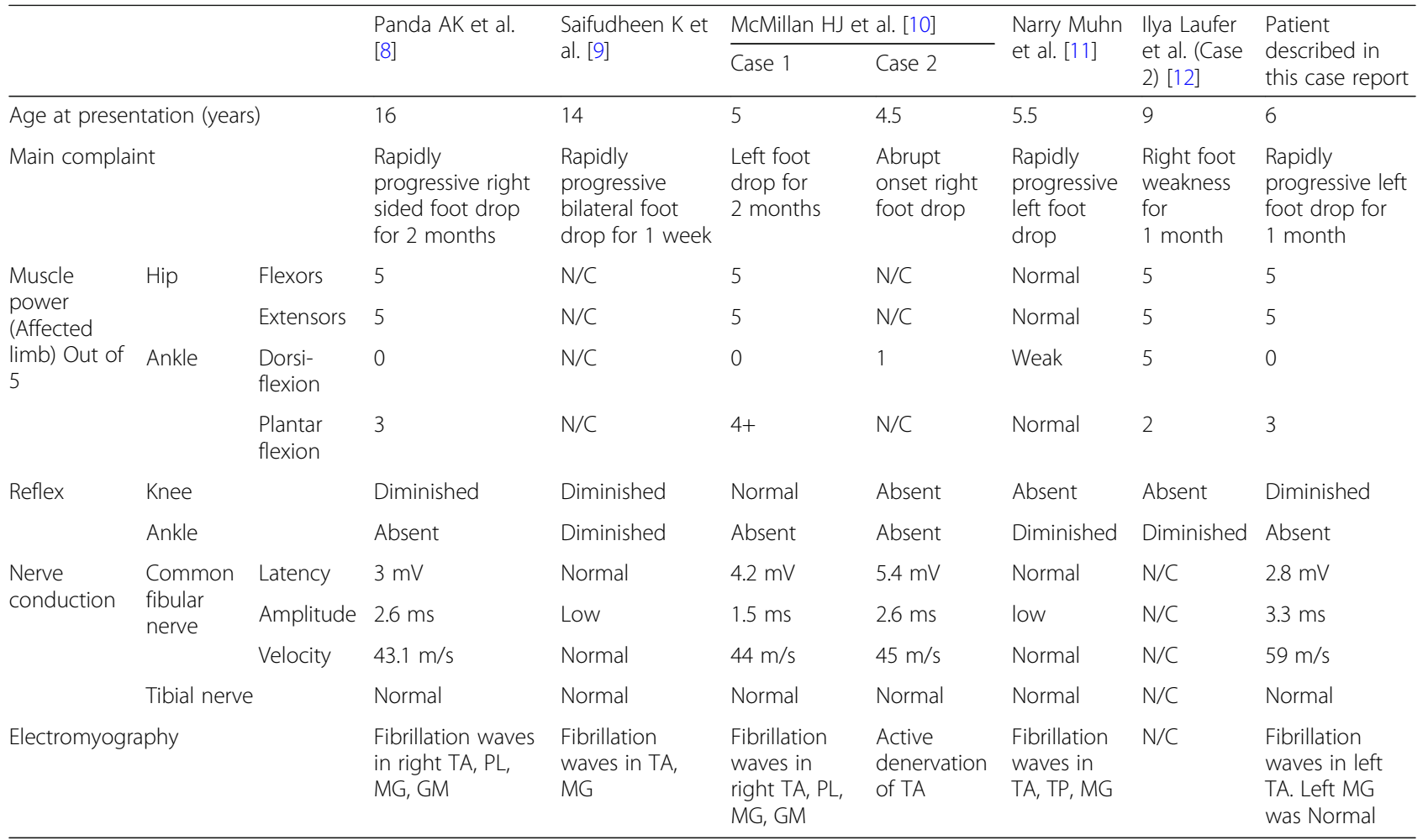

Note: TA Tibialis Anterior, PL Peronius Longus, MG Medial Gastrocnemius, GM Gluteus Medius, TP Tibialis Posterior, N/C Not Commented

adulthood. It is characterized by displacement of cerebellar tonsils below the level of the foramen magnum which results in impaction of the foramen magnum, compression of the cervicomedullary junction by the herniating tonsils and interruption of the cerebrospinal fluid (CSF) through the region $[2,3]$. Disordered CSF flow may result in syringomyelia which usually presents with 'central cord symptoms' - numbness followed by the development of atrophy and weakness in the upper extremities. It can have a combination of upper motor and lower motor neuron lesion feature $[4,5]$.

Our patient did not demonstrate any of the usual presenting symptoms or signs of Chiari malformation type 1 or syringomyelia. Instead, the only presenting clinical features were abnormality in gait and progressive unilateral foot drop. The initial clinical examination and nerve conduction test suggested a lumbar spine pathology however ipsilateral absence of superficial abdominal reflexes suggested a lesion at the thoracic level or above. MRI scan revealed the diagnosis of holocord syrinx with underlying Chiari malformation type 1 .

Chiari malformation type 1 and associated holocord syrinx presenting as foot drop is extremely rare and only few case reports are found in the literature (Table 1). The limited number of patients who had presented with foot drop demonstrates variable physical signs and has marked diversity in neurophysiological abnormalities suggesting variable sites of involvement.

Early diagnosis of Chiari malformation type- 1 is pivotal as prognosis after the surgery depends on the extent of the neurological deficit prior to the surgery. Our patient is awaiting surgery and has an excellent prognosis $[6,7]$. In conclusion, this case highlights the importance of considering broad differential diagnosis for foot drop and value of the complete neurological examination including superficial reflexes in arriving at a diagnosis.

\section{Abbreviations}

MUP: Motor unit potentials; EMG: Electromyography; CSF: Cerebrospinal fluid: TA: Tibialis Anterior; PL: Peronius Longus; MG: Medial Gastrocnemius; GM: Gluteus Medius; TP: Tibialis Posterior; N/C: Not Commented

\section{Acknowledgements}

I acknowledged all the persons who supported for management of this child in our institution and during the manuscript writing specially to the radiology department for providing the photos.

\section{Funding}

No funding.

Availability of data and materials

Data sharing is not applicable to this article as no datasets were generated or analysed during the current study.

\section{Authors' contributions}

All authors CJ, LF and SM contribute in managing, during the work up plan of the patient and writing the manuscript. All authors read and approved the manuscript before the submission. 
Ethics approval and consent to participate

Not applicable.

\section{Consent for publication}

Informed written consent was taken from the parents.

\section{Competing interests}

The authors declare that they have no competing interests.

\section{Publisher's Note}

Springer Nature remains neutral with regard to jurisdictional claims in published maps and institutional affiliations.

\section{Author details}

${ }^{1}$ North Colombo Teaching Hospital, Ragama, Sri Lanka. ${ }^{2}$ Colombo, Sri Lanka. ${ }^{3}$ District General Hospital, Negombo, Sri Lanka. ${ }^{4}$ University of Kelaniya, Kelaniya, Sri Lanka.

Received: 30 January 2017 Accepted: 29 January 2018

Published online: 07 February 2018

\section{References}

1. Greenberg MS. Chiari Malformation. In: Handbook of Neurosurgery. New york: Thieme; 2006. p. 103-9.

2. Speer MC, George TM, Enterline DS, Franklin A, Wolpert CM, Milhorat TH. A genetic hypothesis for Chiari I malformation with or without syringomyelia. Neurosurg Focus. 2000;8(3):E12.

3. Boyles AL, Enterline DS, Hammock PH, Siegel DG, Slifer SH, Mehltretter L, Gilbert JR, Hu-Lince D, Stephan D, Batzdorf U, et al. Phenotypic definition of Chiari type I malformation coupled with high-density SNP genome screen shows significant evidence for linkage to regions on chromosomes 9 and 15. Am J Med Genet A. 2006;140(24):2776-85.

4. Milhorat TH, Bolognese PA, Nishikawa M, McDonnell NB, Francomano CA. Syndrome of occipitoatlantoaxial hypermobility, cranial settling, and chiari malformation type I in patients with hereditary disorders of connective tissue. J Neurosurg Spine. 2007;7(6):601-9.

5. Tubbs RS, Lyerly MJ, Loukas M, Shoja MM, Oakes WJ. The pediatric Chiari I malformation: a review. Childs Nerv Syst. 2007;23(11):1239-50.

6. Greenberg JK, Yarbrough CK, Radmanesh A, Godzik J, Yu M, Jeffe DB, Smyth MD, Park TS, Piccirillo JF, Limbrick DD. The Chiari severity index: a preoperative grading system for Chiari malformation type 1. Neurosurgery. 2015;76(3):279-85. discussion 285

7. Pomeraniec IJ, Ksendzovsky A, Awad AJ, Fezeu F, Jane JA Jr. Natural and surgical history of Chiari malformation type I in the pediatric population. J Neurosurg Pediatr. 2016;17(3):343-52.

8. Panda AK, Kaur M. Rapidly progressive foot drop: an uncommon and underappreciated cause of Chiari I malformation and holocord syrinx. BMJ Case Rep. 2013;2013. https://doi.org/10.1136/bcr-2013-009644.

9. Saifudheen K, Jose J, Gafoor VA. Holocord syringomyelia presenting as rapidly progressive foot drop. J Neurosci Rural Pract. 2011;2(2):195-6.

10. McMillan HJ, Sell E, Nzau M, Ventureyra EC. Chiari 1 malformation and holocord syringomyelia presenting as abrupt onset foot drop. Childs Nerv Syst. 2011;27(1):183-6.

11. Muhn N, Baker SK, Hollenberg RD, Meaney BF, Tarnopolsky MA. Syringomyelia presenting as rapidly progressive foot drop. J Clin Neuromuscul Dis. 2002;3(3): 133-4.

12. Laufer I, Engel M, Feldstein N, Souweidane MM. Chiari malformation presenting as a focal motor deficit. Report of two cases. J Neurosurg Pediatr. 2008;1 (5):392-5.

\section{Submit your next manuscript to BioMed Central and we will help you at every step:}

- We accept pre-submission inquiries

- Our selector tool helps you to find the most relevant journal

- We provide round the clock customer support

- Convenient online submission

- Thorough peer review

- Inclusion in PubMed and all major indexing services

- Maximum visibility for your research

Submit your manuscript at www.biomedcentral.com/submit
Biomed Central 